\title{
SER MÉDICO DESDE DOS LENGUAJES DIFERENTES: EL LITERARIO Y EL CINEMATOGRÁFICO
}

\section{To be a doctor from two different languages: literary and cinematographic}

\author{
María Eugenia D'OTTAVIO CALLEGARI ${ }^{1}$; Guillermo Enrique D'OTTAVIO CALLEGARI²; Alberto Enrique \\ D'OTTAVIO CATTANI ${ }^{3}$
}

\begin{abstract}
${ }^{1}$ Universidad del Gran Rosario, Rosario (Santa Fe) (Argentina). ${ }^{2}$ Instituto Gamma, Hospital Privado de Rosario y Hospital Italiano Garibaldi, Rosario (Santa Fe) (Argentina). ${ }^{3}$ Facultad de Ciencias Médicas y Consejo de Investigaciones de la Universidad Nacional de Rosario, Rosario (Santa Fe) (Argentina).
\end{abstract}

e-mail: aedottavio@hotmail.com

Fecha de recepción: 7 de enero de 2020

Fecha de aceptación: 10 de febrero de 2020

Fecha de publicación: 15 de septiembre 2020

\begin{abstract}
Resumen
El presente trabajo aborda la condición de ser médico desde dos lenguajes diferentes: el literario y el cinematográfico, sintetizando aspectos registrados en la bibliografía sobre este tema y cotejándolos con lo citado en un filme documental español reciente que alterna históricas filmaciones de médicos virtuosos con las respectivas aportaciones de destacados profesionales de la Medicina.

Palabras clave: medicina; lenguaje; cine; literatura.
\end{abstract}

\section{Abstract}

This paper addresses the condition of being a doctor from two different languages: literary and cinematographic by synthesizing aspects bibliographically recorded on this issue and comparing it with that cited in a recent Spanish documentary film where historical filming of virtuous doctors alternates with the corresponding considerations of leading medical professionals.

Key words: medicine; language; cinema; literature. 


\section{SER MÉDICO DESDE DOS LENGUAJES DIFERENTES: EL LITERARIO Y EL CINEMATOGRÁFICO MARÍA EUGENIA D'OTTAVIO CALLEGARI; GUILLERMO ENRIQUE D'OTTAVIO CALLEGARI; ALBERTO ENRIQUE D'OTTAVIO CATTANI}

\section{Ser médico desde el lenguaje literario}

La bibliografía registra diversas publicaciones sobre el desafío de ser médico. Todas, a su modo, constituyen un viaje a lo largo de la carrera que conduce a tal meta y analizan, en mayor o menor grado, facetas ligadas con la decisión por Medicina, su ingreso, cursado y egreso, los procesos de enseñanza y de aprendizaje y las evaluaciones, el diseño, ejecución y evaluación de los currículos médicos, la investigación, docencia y asistencia, los razonamientos deductivos, inductivos, abductivos y analógicos involucrados en diagnóstico e investigación y las insoslayables bioética y deontología que la profesión exige durante el grado y el postgrado ${ }^{1-6}$.

En esencia, estas obras plantean que se es médico indagando y creando nuevos conocimientos médicos como investigadores, trasmitiéndolos como docentes o bien aplicándolos, como médicos asistenciales. Además, sostienen que cualquiera sea la práctica profesional, debe sumarse a la ineludible idoneidad: ético proceder, honestidad intelectual, constante actualización y superación, sana curiosidad, respeto por el prójimo, desinteresado servicio, permanente compromiso y exigible empatía. Finalmente, abogan para que nada de lo humano le resulte ajeno a quien desea serlo pues, según apostillara el anatomopatólogo decimonónico D. José de Letamendi y Manjarrés: quien sólo de Medicina sabe, ni de Medicina sabe.

\section{Ser médico desde el lenguaje cinematográfico}

El título de un filme documental español, presentado en el Colegio de Médicos de Madrid en marzo 2017, alude precisa y taxativamente a ello.

La idea original correspondió al Grupo de Trabajo de Bioética de la Sociedad Española de Medicina Interna (SEMI), fue realizado con el patrocinio conjunto del Instituto de Ética Clínica Francisco Vallés de la Universidad Europea de Madrid (UEM) y de la susodicha Sociedada.

a. Posteriormente se sumó Univadis, portal médico de referencia. Ha tenido difusión en España y se

\section{Ficha técnica}

Título: Ser médico.

País: España.

Año: 2017.

Director: Benjamín Herreros.

Música: Miguel Herreros Ruiz-Valdepeñas.

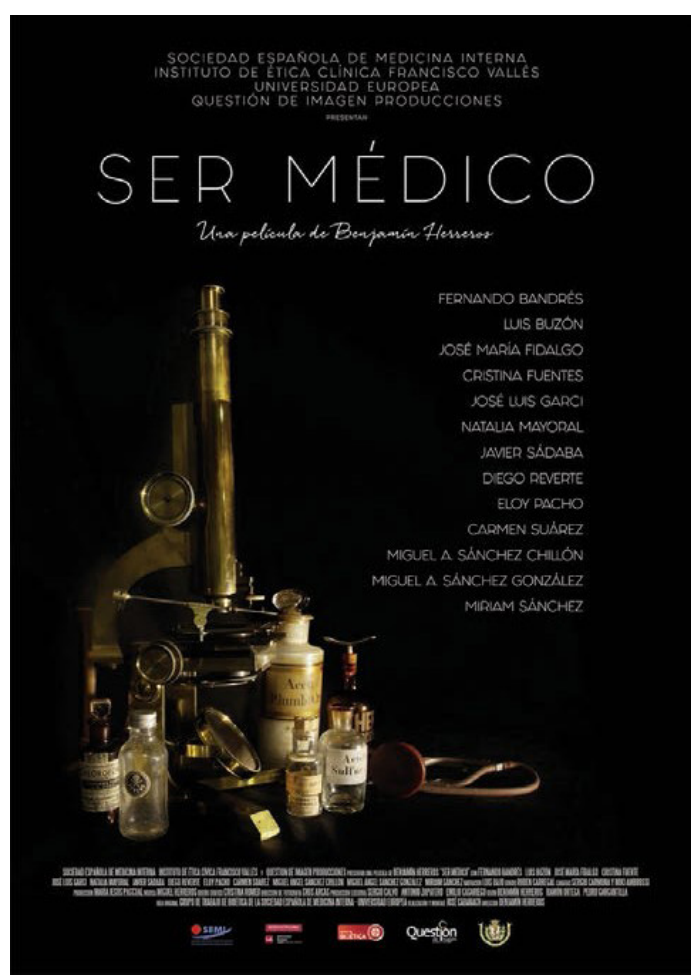

Cartel español.

Fotografía: Chus Arcas.

Montaje: José Cabanach.

Narración: Luis Bajo.

Guion: Benjamín Herreros, Ramón Ortega, Pedro Gargantilla.

Intérpretes: Fernando Bandrés Moya, Luis Buzón, José María Fidalgo, Cristina Fuentes, José Luis Garci, Natalia Mayoral, Javier Sádaba, Diego

ha hallado referencia sobre su eventual inscripción en un festival neoyorquino de cortometrajes. 


\section{SER MÉDICO DESDE DOS LENGUAJES DIFERENTES: EL LITERARIO Y EL CINEMATOGRÁFICO \\ MARÍA EUGENIA D'OTTAVIO CALLEGARI; GUILLERMO ENRIQUE D'OTTAVIO CALLEGARI; ALBERTO ENRIQUE D'OTTAVIO CATTANI}

Reverte, Eloy Pacheco, Carmen Suárez, Miguel Ángel Sánchez Chillón, Miguel Ángel Sánchez González, Miriam Sánchez.

Color: color.

Duración: 26 minutos.

Género: documental.

Producción: María Jesús Pascual.

Sinopsis: «El documental Ser Médico está coproducido por el Instituto de Ética Clínica Francisco Vallés - UE y la Sociedad Española de Medicina Interna (SEMI), pretende destacar las virtudes que debe tener un médico para ser un buen médico. "Yo nací para médico y no lo cambiaría por nada". "Es la única profesión que merece la pena". "La razón de ser médico es el paciente". Estas son algunas de las afirmaciones que cierran el documental. Estructurado en siete virtudes que debe tener el médico (voluntad, sacrificio, investigación, humanidad, excelencia, universalidad y compromiso)».

\section{Enlace:}

https://www.institutoeticaclinica.org/documental-ser- medico/ (bilingüe)

De manera sintética, un/-a buen/-a médico/-a, según sus autores, debe poseer: voluntad, sacrificio, investigación, humanidad, excelencia, universalidad y compromiso. A guisa de ejemplo, intercalan históricas filmaciones de quienes sobresalieron en cada uno de tales atributos, sin excluir en modo alguno la posesión de los restantes. Así, desfilan sucesivamente los Dres. Santiago Ramón y Cajal, histólogo y Premio Nobel 1906 (la voluntad), Juan Negrín, fisiólogo colaborador de Cajal y presidente del Gobierno durante la II República (el sacrificio), el científico Severo Ochoa, Premio Nobel 1959 y discípulo de Negrín (la investigación), el endocrinólogo y pensador Gregorio Marañón (la humanidad) ${ }^{\mathrm{b}}$, el internista e investigador Carlos Jiménez Díaz, pionero de la investigación transaccional (la excelencia) ${ }^{7}$, el

b. A él suele atribuírsele erróneamente el aforismo de Letamendi. internista y Secretario de Estado para la Salud (1979-1980) José María Segovia de Arana, uno de los fundadores del sistema de residencias para formación de posgrado en Medicina (la universalidad) y el catedrático Luis Buzón (compromiso). Cada atributo es enriquecido por los testimonios de Fernando Bandrés Moya (Profesor titular de Toxicología y Legislación Sanitaria en la Facultad de Medicina de la Universidad Complutense de Madrid), José Luis Garci (cineasta y paciente), José María Fidalgo (médico y líder sindical), Javier Sádaba (filósofo y escritor), Miguel Ángel Sánchez González (historiador de la medicina), Miguel Ángel Sánchez Chillón (Presidente del Ilustre Colegio de Médicos de Madrid -ICOMEM-), y los de otros profesionales (Carmen Suárez, Cristina Fuentes, Luis Buzón, Miriam Sánchez, Diego Reverte. Natalia Mayoral y Eloy Pacheco). El cierre se hace con D. Santiago Ramón y Cajal sentándose en un banco de plaza mientras se escucha este párrafo que le pertenece:

Puesto que vivimos en pleno misterio, luchando contra las fuerzas desconocidas, tratemos en lo posible de esclarecerlo. Concluida nuestra labor, seremos olvidados como la semilla en el surco, pero algo nos consolará: el considerar que nuestros remotos descendientes, nos deberán un poco de su dicha. Y que, gracias a nuestro esfuerzo, el mundo resultará algo más agradable e inteligible.

¿Antagonismo o complementariedad interlingüística?

Las obras literarias del género ensayo ${ }^{1-6}$ abordan distintas facetas del proceso de ser médico al igual que lo hacen determinadas experiencias pedagógico-didácticas ${ }^{8}$ y obras del género novela ${ }^{9}$. Todas ellas exigen esfuerzo comprensivo, en mayor o menor grado, por su extensión, su reducción a lo visual y su contenido librado a la imaginación, así como por requerir considerable compromiso y, en ciertos casos, poseer elevado grado de abstracción. Ello conlleva el riesgo anexo de distracción y de deserción lectora, más allá del

Rev. Med. Cine. 2020; 16(3), 193-197 Ediciones Universidad de Salamanca / @®@® J. Med. Mov., 2020; 16 (3), 193-197 


\section{SER MÉDICO DESDE DOS LENGUAJES DIFERENTES: EL LITERARIO Y EL CINEMATOGRÁFICO \\ MARÍA EUGENIA D'OTTAVIO CALLEGARI; GUILLERMO ENRIQUE D'OTTAVIO CALLEGARI; ALBERTO ENRIQUE D'OTTAVIO CATTANI}

denuedo puesto por los autores a fin de simplificar su escrito y de tornarlo atractivo.

En contraste, la cinematografía que, como el lenguaje anterior, mucho ha aportado, directa e indirectamente, sobre este particular ${ }^{10}$, superpone espacio, ritmo, movimiento, sonido, montaje (base de este lenguaje), iluminación, tono y color. Es puramente audiovisual, dinámica, tiene tiempos más acotados, adaptaciones o argumentos resumidos y potencialmente amenos e imágenes atrayentes. Precisamente, el documental en estudio pone el acento en determinados valores, cultivables por cursantes y graduados, mediante sorprendentes filmaciones históricas de figuras ejemplares alternadas con ágiles y complementarias aportaciones por parte de entrevistados.

En tal contexto, literatura y cine, lenguajes con distintos modos, medios y ritmos de narración, además de proveer diferentes posibilidades de tratamiento sobre qué implica ser médico, evidencian una enriquecedora interacción mutua que, al margen del sentido en que ésta ocurra, obra en bien de tal objetivo.

\section{Referencias}

1. Konner M. Becoming a doctor. A journey of initiation in medical school. London: Penguin Books; 1987.
2. D'Ottavio AE. Ser médico. Reflexiones sobre la formación y la práctica médicas. Rosario: Homo Sapiens Ediciones; 2001.

3. Agrest A. Ser médico ayer, hoy y mañana. Puentes entre el paciente, la medicina y la sociedad. Buenos Aires: Libros del Zorzal; 2008.

4. Jaim Etcheverry G, Buzzi A, Agrest A, Maglio F, Del Bosco G, Ortiz Z, et al. ¿Por qué ser médico hoy? Puentes entre la formación y la práctica médicas Buenos Aires: Libros del Zorzal; 2009.

5. Vilardell i Tarrés M. Ser Metge. Barcelona: Plataforma Editorial; 2009.

6. Zarco Rodríguez J. El arte de ser médico. Sanar, cuidar, acompañar. Barcelona: Editorial Planeta; 2013.

7. Culebras JM, Franco-López A. Los orígenes de la Fundación Jiménez Díaz. JONNPR. 2019; 4(8): 829-55.

8. Steiner-Hofbauer V, Schrank B, Holzinger A. What is a good doctor? Wien Med Wochenschr 2018; 168 (15-16): 398-405.

9. D'Ottavio AE. Archibald Joseph Cronin: a WritingDoctor between Literature and Film. J Med Mov. 2009; 5 (2): 59-65.

10. D’Ottavio AE, García Sánchez JE, García Sánchez $E$. The cinema as a fostering tool for health area undergraduates. Rev Med Cine [Internet] 2019; 15(2): 101-5. 


\section{SER MÉDICO DESDE DOS LENGUAJES DIFERENTES: EL LITERARIO Y EL CINEMATOGRÁFICO \\ MARÍA EUGENIA D'OTTAVIO CALLEGARI; GUILLERMO ENRIQUE D'OTTAVIO CALLEGARI; ALBERTO ENRIQUE D'OTTAVIO CATTANI}

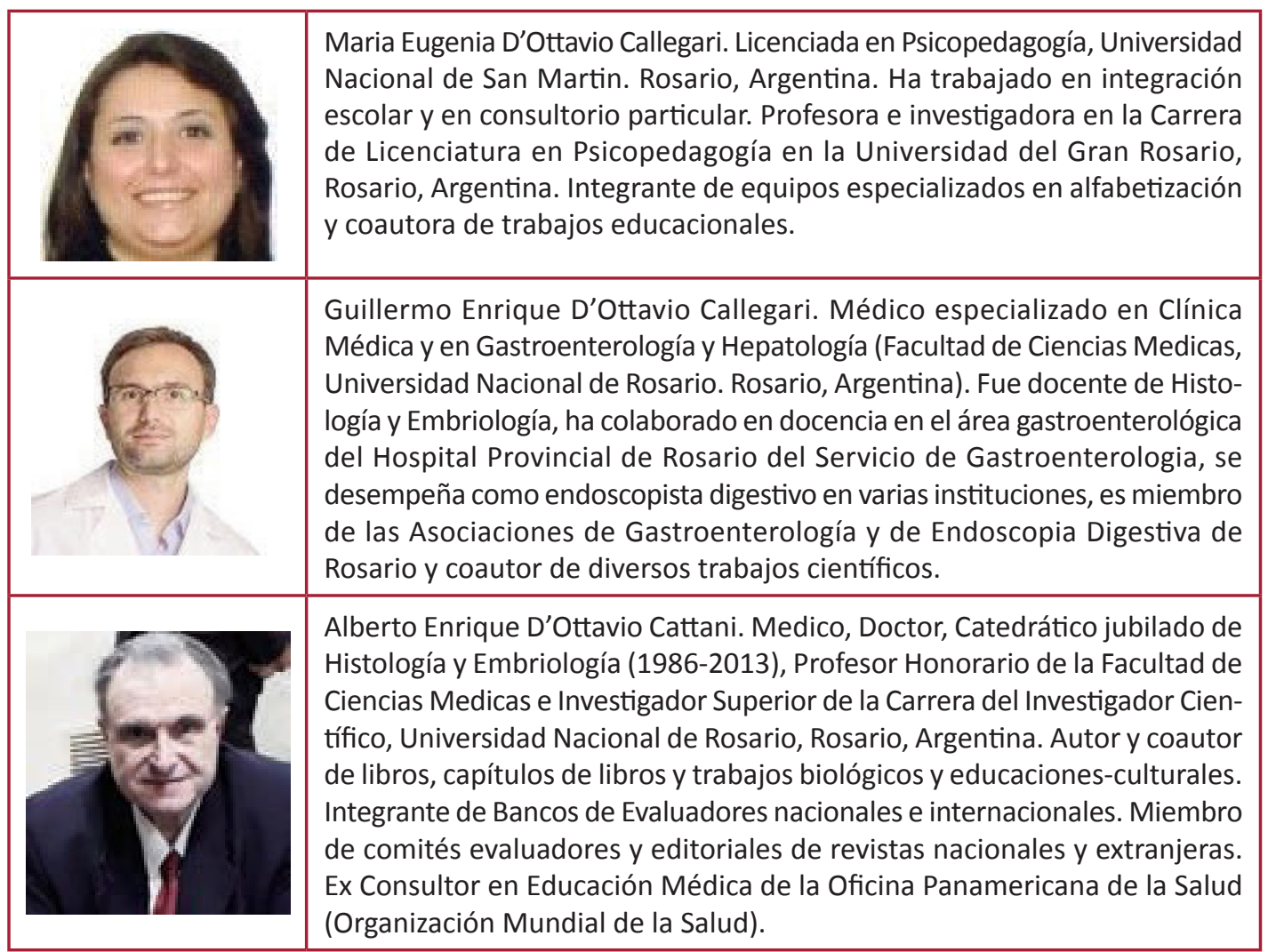

